Check for updates

Cite this: RSC Adv., 2019, 9, 1752

Received 6th November 2018

Accepted 21st December 2018

DOI: $10.1039 / \mathrm{c} 8 \mathrm{ra} 09175 \mathrm{~g}$

rsc.li/rsc-advances

\title{
First principles study of surface properties and oxygen adsorption on the surface of $\mathrm{Al}_{3} \mathrm{Ti}$ intermetallic alloys
}

\begin{abstract}
Yang Zhou, (D) *a Huihui Xiong, ${ }^{a}$ Yanhong Yin ${ }^{b}$ and Shengwen Zhong ${ }^{* b}$
The density functional theory (DFT) method was applied to study the structural, electronic and surface properties of low-index $\mathrm{Al}_{3} \mathrm{Ti}$ intermetallic materials. The surface energies and electronic structures of those surfaces were also discussed in this study. The calculated surface energies of the low-index surfaces of $\mathrm{Al}_{3} \mathrm{Ti}$ indicated that nonstoichiometric (110) surface with $\mathrm{Al}$ termination was the most stable surface. On this basis, the oxygen adsorption behavior of the (110)-Al surface was further studied to clarify the antioxidant mechanism of $\mathrm{Al}_{3} \mathrm{Ti}$ intermetallic alloys. Various adsorption sites of oxygen atoms on the (110)-Al surface were considered to identify the most stable adsorption configurations. According to the calculation results of adsorption energies, it was found that stability was maximized when oxygen was adsorbed at the Al-Al bridge site. Meanwhile, a density of state study indicated that adsorption of oxygen on the (110)-Al surface preferred to bond with $\mathrm{Al}$ atoms rather than Ti atoms.
\end{abstract}

\section{Introduction}

Ti-Al intermetallic alloys are high temperature resistant structural materials with great potential in both aerospace and automotive applications and have been attracting particular attention. ${ }^{\mathbf{1 - 4}}$ Compared with other two intermetallic alloys, namely, TiAl and $\mathrm{Ti}_{3} \mathrm{Al}$, the $\mathrm{Al}_{3} \mathrm{Ti}$ alloy has the lowest density, largest elastic modulus, moderately high melting temperature and superior oxidation resistance., ${ }^{5,6}$ The oxidation and corrosion behavior of $\mathrm{Al}_{3}$ Ti-based intermetallic compounds has been extensively investigated via experiments using high temperature conditions. ${ }^{7-12}$ Chen $^{\mathbf{1 1}}$ reported that Al-Ti alloys with an $\mathrm{Al}$ content of $50 \%$ shows low corrosion resistance at high temperatures, and the formation of mixed $\mathrm{TiO}_{2}$ and $\mathrm{Al}_{2} \mathrm{O}_{3}$ layers further decreased the corrosion resistance. Meanwhile, Parfitt $^{12}$ studied the high-temperature oxidation behavior of $\mathrm{Al}_{3} \mathrm{Ti}$ intermetallic alloys in an oxygenated atmosphere and found that an $\alpha-\mathrm{Al}_{2} \mathrm{O}_{3}$ layer formed on the alloy surface in the temperature range of $700-1200{ }^{\circ} \mathrm{C}$, and this protective layer suppressed oxygen diffusion and slowed the oxidation rate. Recently, attempts had been made to further improve the oxidation resistance of $\mathrm{Al}_{3} \mathrm{Ti}$ alloy through alloying with $\mathrm{Cr},{ }^{13,14}$ $\mathrm{Mn},{ }^{12} \mathrm{Zr},{ }^{15}$ etc. For example, an investigation by Yamaguchi ${ }^{\mathbf{1 6}}$ showed that $\mathrm{Cu}$-substituted $\mathrm{Al}_{3} \mathrm{Ti}$ alloys exhibit very low oxidation resistance, while $\mathrm{Mn}, \mathrm{Ag}, \mathrm{Fe}, \mathrm{Cr}$-substituted alloys

${ }^{a}$ Engineering Research Institute Jiangxi University of Science and Technology, 86 Hongqi Road, Ganzhou 341000, PR China. E-mail:yangzhou1998@126.com

${ }^{b}$ Key Laboratory of Power Batteries \& Relative Materials, Ganzhou 341000, PR China. E-mail: zhongshw@126.com exhibited good oxidation resistance. All the studies showed that the oxidation behaviors of the $\mathrm{Al}_{3} \mathrm{Ti}$ alloys depended on its surface properties. Therefore, it was crucial to clarify the adsorption, dissolution, and diffusion properties of oxygen on the surface of $\mathrm{Al}_{3} \mathrm{Ti}$ alloy, which can reveal the mechanism of its oxidation. However, investigating the high-temperature corrosion of the alloys was challenging and could not be achieved by conventional methods.

First principles computations provided a suitable means to shed light on the physical and chemical surface properties. The adsorption of atomic and molecular oxygen on the surface of several $\mathrm{Ti}-\mathrm{Al}$ intermetallic alloys such as $\gamma$-TiAl, ${ }^{17,18}$ $\mathrm{Ti}_{3} \mathrm{Al},{ }^{19-21}$ and the $\operatorname{TiAl}(111) / \mathrm{Al}_{2} \mathrm{O}_{3}(0001)$ interface ${ }^{22}$ were investigated theoretically using density functional theory (DFT) calculations. $\mathrm{Liu}^{23}$ used the DFT method to study the effect of surface self-segregation on the adsorption of oxygen by the $\gamma$-TiAl(111) surface, showing that Al self-segregation at the surface can enhance the interaction between $\mathrm{O}$ and $\mathrm{Al}$ atoms. Kulkova ${ }^{24}$ employed DFT calculations to explore the adsorption and diffusion of oxygen on $\gamma$-TiAl(001) and (100) surfaces, revealing the oxidation mechanism of $\gamma$-TiAl alloys. In this paper, the structural, electronic and surface properties of low-index surfaces of $\mathrm{Al}_{3} \mathrm{Ti}$ intermetallic alloy were studied by using the CASTEP code, which is based on the density functional theory and the periodical slab model. The most favorable adsorption site of oxygen atoms was determined by calculating the adsorption energies. According to the calculated state of density analysis, a bonding mechanism for the oxygen atoms and $\mathrm{Al}$ atoms was also presented, which was consistent with the experimental results. 


\section{Calculation method and details}

All calculations in this study were performed using the Cambridge Serial Total Energy Package (CASTEP) code ${ }^{25,26}$ which is based on the density functional theory. The interactions between the ionic core and valence electrons was modeled via the plane-wave ultra-soft pseudopotential method. ${ }^{27}$ The valence electrons of the atoms chosen were $\mathrm{Ti} 3 \mathrm{~s}^{2} 3 \mathrm{p}^{6} 3 \mathrm{~d}^{2} 4 \mathrm{~s}^{2}$ and Al $3 \mathrm{~s}^{2} 3 \mathrm{p}^{1}$. A generalized gradient approximation (GGA) of the Perdew-Burke-Ernzerhof (PBE) functional ${ }^{28}$ was employed to treat the exchange-correlation interactions. The Brillouin zone was sampled with the Monkhorst-Pack $k$-point grid. The cutoff energy and $k$-point sampling were set as $380 \mathrm{eV}$ and $7 \times 7 \times 3$ for the bulk, and $3 \times 3 \times 1$ for all slabs, respectively.

To reveal the interaction mechanisms between oxygen and $\mathrm{Al}_{3} \mathrm{Ti}$, the adsorption behavior of the oxygen atom was studied with different sites on the most stable surface of $\mathrm{Al}_{3} \mathrm{Ti}((110)-\mathrm{Al}$ surface, see Section 3.3). Fig. 1a shows the slab model of oxygen adsorption on the (110)-Al surface, which consisted of seven layers containing 56 atoms and separated with $15 \AA$ spacing of vacuum. The atoms located on the three bottom layers of the slab were fixed, while the atoms on the top-most four layers and oxygen atoms were allowed to relax. To prevent the mutual effect of the adsorbed oxygen atoms, the supercell of the (110)-Al surface model (Fig. 1b) was enlarged by $(2 \times 2)$ along the surface. The surfaces were fully relaxed before the oxygen adsorption calculations were performed.

The single oxygen atom was placed on five possible adsorption sites of the (110)-Al surface of $\mathrm{Al}_{3} \mathrm{Ti}$. These sites included the Al-top site, the bridge1 site, the bridge2 site, the Al-hollow site, and the Ti-hollow site, which are defined by the location of the oxygen atom, respectively, as follows: at the top of $\mathrm{Al}, \mathrm{Al}-$ $\mathrm{Al}(\mathrm{II})$ in the surface layer, $\mathrm{Al}$ (II)- $\mathrm{Al}$ (III) in the surface layer, $\mathrm{Al}$ in the second surface layer, and $\mathrm{Ti}$ in the second surface layer. The adsorption energy $\left(E_{\text {ads }}\right)$ was calculated from the following equation: ${ }^{29}$

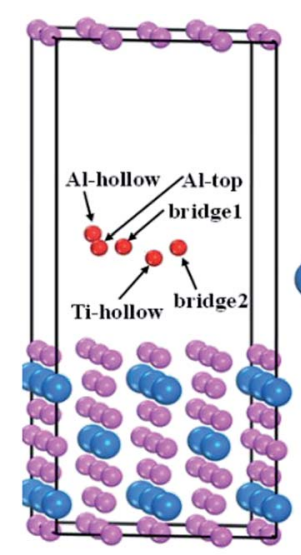

(a)

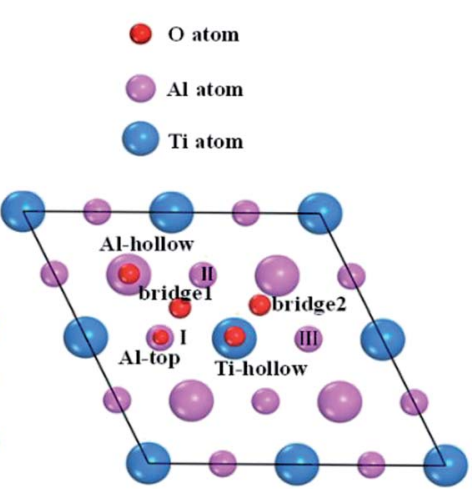

(b)
Fig. 1 Schematic structure of the possible oxygen adsorption sites on an Al-terminated (110) surface: (a) side view, (b) top view. In (b), the small pink balls represent Al atoms in the surface layer, and the big pink and blue balls represent $\mathrm{Al}$ and $\mathrm{Ti}$ atoms in the subsurface layer, respectively.

$$
E_{\mathrm{ads}}=E_{\mathrm{O} / \mathrm{Al}_{3} \operatorname{Ti}(110)}-E_{\mathrm{Al}_{3} \mathrm{Ti}(110)}-E_{\mathrm{O}}
$$

where $E_{\mathrm{O} / \mathrm{Al}_{3} \mathrm{Ti}(110)}$ and $E_{\mathrm{Al}_{3} \mathrm{Ti}(110)}$ were the total energies of the (110)-Al surface with and without oxygen adsorption, respectively, and $E_{\mathrm{O}}$ was the energy of a free oxygen atom, which was calculated by placing an $\mathrm{O}$ atom into an empty cell of $10 \times 10 \times$ $10 \AA$. The spin polarization was considered during the calculation process and the obtained value was $-431.79 \mathrm{eV}$. A negative adsorption energy indicated that the adsorption was thermopositive and the adsorption site was stable. Moreover, larger absolute values of adsorption energy indicated more stable adsorption site. The possible stable adsorption sites of oxygen atom at the top, bridge and hollow locations could be determined by optimizing the structural parameters.

\section{Results and discussion}

\subsection{Bulk properties}

To guarantee the accuracy of the calculations performed in this study, the lattice constant and formation enthalpy of $\mathrm{Al}_{3} \mathrm{Ti}$ were first calculated. The formation enthalpy $\left(\Delta H_{\mathrm{Al}_{3} \mathrm{Ti}}\right)$ of $\mathrm{Al}_{3} \mathrm{Ti}$ could be obtained using the following equation:

$$
\Delta H_{\mathrm{Al}_{3} \mathrm{Ti}}=\left(E_{\mathrm{Al}_{3} \mathrm{Ti}}-3 E_{\mathrm{Al}}-E_{\mathrm{Ti}}\right) / 4
$$

where $E_{\mathrm{Al}_{3} \mathrm{Ti}}$ was the total energy of an $\mathrm{Al}_{3} \mathrm{Ti}$ unit cell, and $E_{\mathrm{Al}}$ and $E_{\mathrm{Ti}}$ were the energies of a single $\mathrm{Ti}$ and $\mathrm{Al}$ atom in the bulk state, respectively.

The calculated structural parameters and formation enthalpy of $\mathrm{Al}_{3} \mathrm{Ti}$ intermetallic alloy were shown in Table 1 . The lattice constants " $a$ " and " $c$ " of bulk $\mathrm{Al}_{3}$ Ti were $3.8501 \AA$ and $8.6274 \AA$, which were in good agreement with the experimental results published in ref. 32 and 34, respectively. Additionally, the formation enthalpy obtained in our study was $-153.82 \mathrm{~kJ} \mathrm{~mol}^{-1}$, which matched well with the other calculated and experimental results. Meanwhile, the negative value for the formation enthalpy of $\mathrm{Al}_{3} \mathrm{Ti}$ suggested that tetragonal $\mathrm{Al}_{3} \mathrm{Ti}$ was a stable state. Therefore, the calculation methods could guarantee accuracy and reliability of subsequent calculations.

Tetragonal $\mathrm{Al}_{3} \mathrm{Ti}$ belonged to space group $14 / \mathrm{mmm}$. The Ti, $\mathrm{Al} 1$ and $\mathrm{Al} 2$ atoms occupy $(0,0,0),(0,0,0.5)$ and $(0,0.5,0.25)$ Wyckoff sites, respectively. Fig. 2 presents the total and partial density of states (DOS) distributions of bulk $\mathrm{Al}_{3} \mathrm{Ti}$. The contributions of $\mathrm{Al} 1$ and $\mathrm{Al} 2$ atoms to DOS differed slightly, which was probably due to the different occupied locations. The existence

Table 1 Calculated lattice parameters and formation enthalpy of $\mathrm{Al}_{3} \mathrm{Ti}$ along with previously reported theoretical and experimental data

\begin{tabular}{lllll}
\hline Phase & Method & $a(\AA)$ & $c(\AA)$ & $\begin{array}{l}\text { Formation enthalpy } \\
\left(\mathrm{kJ} \mathrm{mol}^{-1}\right)\end{array}$ \\
\hline \multirow{2}{*}{$\mathrm{Al}_{3} \mathrm{Ti}$} & This work & 3.8501 & 8.6274 & -153.82 \\
& GGA-PBE $^{30}$ & 3.868 & 8.628 & -160.40 \\
& GGA-PW91 (ref. 31) $^{32}$ & 3.851 & 8.611 & - \\
& Expt. $^{34}$ & 3.8537 & 8.5839 & -151.20 (ref. 33) \\
& Expt. $^{34}$ & 3.851 & 8.610 & -
\end{tabular}



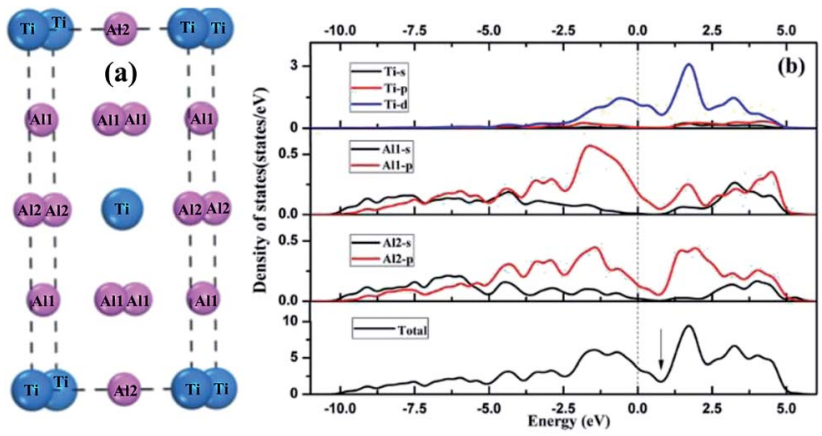

Fig. 2 Crystal structures (a) and density of states (b) of bulk $\mathrm{Al}_{3} \mathrm{Ti}$.

of metallic bonds in the $\mathrm{Al}_{3}$ Ti intermetallic alloy was also proved by the DOS profile across the Fermi level. Moreover, the pseudogap near the Fermi level indicated the existence of covalent bonding, ${ }^{35}$ which was in accordance with the result that covalent interactions were possessed by the $3 \mathrm{~d}$ orbit of $\mathrm{Ti}$ atom and $2 \mathrm{p}$ orbit of $\mathrm{Al}$ atom. ${ }^{36}$

\subsection{Surface electronic properties}

As shown in Fig. 3, the low-index surfaces of $\mathrm{Al}_{3} \mathrm{Ti}$ were constructed as follows: nonstoichiometric surfaces with (a, d) $\mathrm{Al}$ termination and (b, e) AlTi termination, and (c, f) stoichiometric surfaces. The calculated partial density of states (PDOS) and total density of states (TDOS) are shown in Fig. 4. According to the calculated TDOS results, all of the low-index surfaces exhibited metallic properties and a pseudogap near the Fermi level, which is consistent with the DOS of bulk $\mathrm{Al}_{3} \mathrm{Ti}$ (Fig. 2). The PDOS of $\mathrm{Ti}$ and $\mathrm{Al}$ in the inner layers were also similar to those of bulk $\mathrm{Al}_{3} \mathrm{Ti}$, but noticeable changes in the contours of the outermost layer occurred relative to the inner layer. For the nonstoichiometric (001) and (110) surfaces with AlTi termination (Fig. 4b and e), the surface Ti-3d and Al1-2p electrons moved towards the Fermi level, suggesting an increased metallic property and decreased stability. However, the Alterminated surface (Fig. $4 \mathrm{a}$ and d) Al-2p electrons were far
(001)-Al

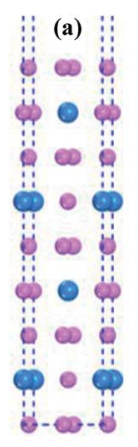

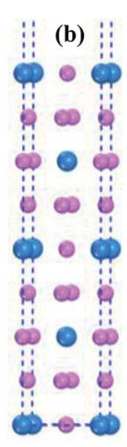

(001)-AITi

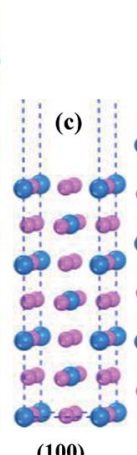

(100)

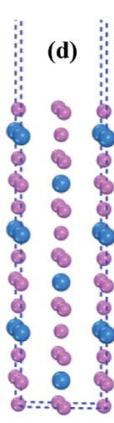

(110)-Al

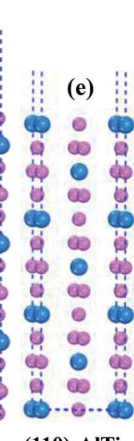

(110)-AITi
Al
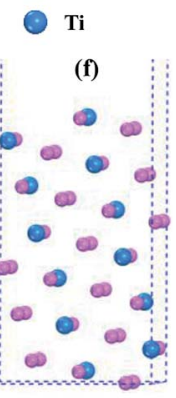

(111)
Fig. 3 The constructed low-index surfaces of $\mathrm{Al}_{3} \mathrm{Ti}$ : (a) non-stoichiometric (001) surface with Al termination, (b) non-stoichiometric (001) surface with AlTi termination, (c) stoichiometric (100) surface, (d) non-stoichiometric (110) surface with Al termination, (e) non-stoichiometric (110) surface with AlTi termination and (f) stoichiometric (111) surface.
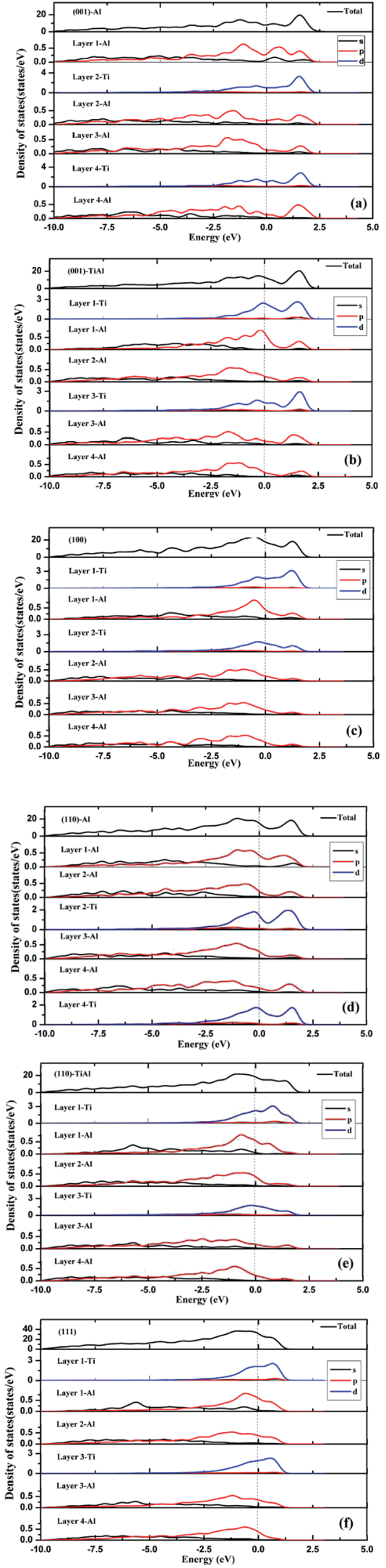

Fig. 4 The TDOS and PDOS of various low-index surfaces: (a) (001)Al, (b) (001)-AlTi, (c) (100), (d) (110)-Al, (e) (110)-AlTi, (f) (111). 


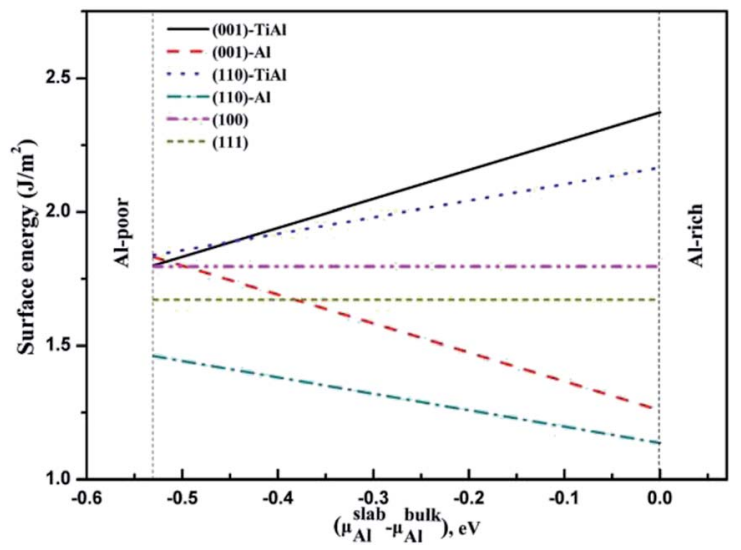

Fig. 5 Relationship between surface energies of low-index surfaces and Al chemical potential.

Table 2 Adsorption energy of oxygen at different sites of the (110)-Al surface

\begin{tabular}{lll}
\hline Surface & Site & $E_{\text {ads }}(\mathrm{eV})$ \\
\hline (110)-Al & Ti-hollow & -5.17 \\
& Al-hollow & -4.53 \\
Al-top & -4.00 \\
& bridge1 & -7.13 \\
& bridge2 & -6.48
\end{tabular}

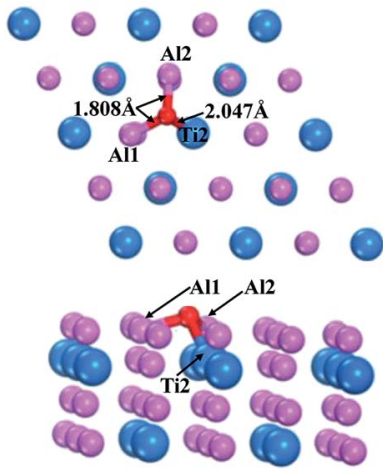

(a)

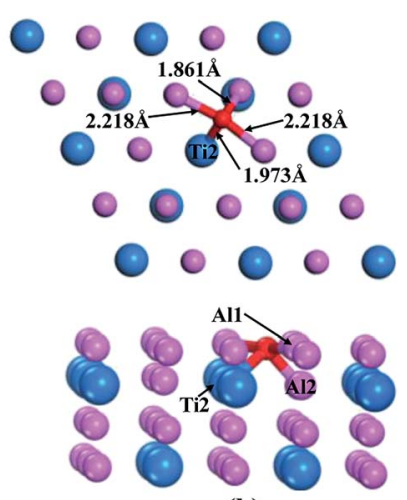

(b)
Fig. 6 Top and side views of $O$ adsorption on bridge1 (a) and bridge2 (b) sites after geometrical optimization.

from the Fermi level, suggesting a decreased metallic property and increased stability. For the two stoichiometric surfaces (Fig. 4c and $\mathrm{f}$ ), the non-localization of the electrons in the surfaces was in the order of $(100)>(111)$ on the basis of the intensity of the DOS, which indicated that the (111) surface was more stable than the (110) surface.

\subsection{Surface energy}

The surface energy $\left(\gamma_{\mathrm{s}}\right)$ was used as a basic parameter to compare the stability of various low-index surfaces, which was calculated from the following equation: ${ }^{37-39}$

$$
\gamma_{\mathrm{s}}=\frac{1}{2 A}\left(E_{\mathrm{slab}}-N_{\mathrm{Ti}} \times \mu_{\mathrm{Al}_{3} \mathrm{Ti}}^{\text {bulk }}-\left(N_{\mathrm{Al}}-3 N_{\mathrm{Ti}}\right) \times \mu_{\mathrm{Al}}^{\text {slab }}\right)
$$

where $E_{\text {slab }}$ refers to the total energy of the relaxed surface; $N_{\mathrm{Ti}}$ and $N_{\mathrm{Al}}$ are the numbers of the $\mathrm{Ti}$ and $\mathrm{Al}$ atoms in the slab, respectively; $\mu_{\mathrm{Al}_{3} \mathrm{Ti}}^{\text {bulk }}$ and $\mu_{\mathrm{Al}}^{\text {slab }}$ are the chemical potentials for bulk $\mathrm{Al}_{3} \mathrm{Ti}$ and $\mathrm{Al}$ atoms in surface slab, respectively; and $A$ is the surface area. The chemical potential of Al was smaller than that of the corresponding bulk substances. Moreover, the chemical potential of $\mathrm{Al}$ was related to the chemical potential of bulk $\mathrm{Al}_{3} \mathrm{Ti}$, which was defined as:
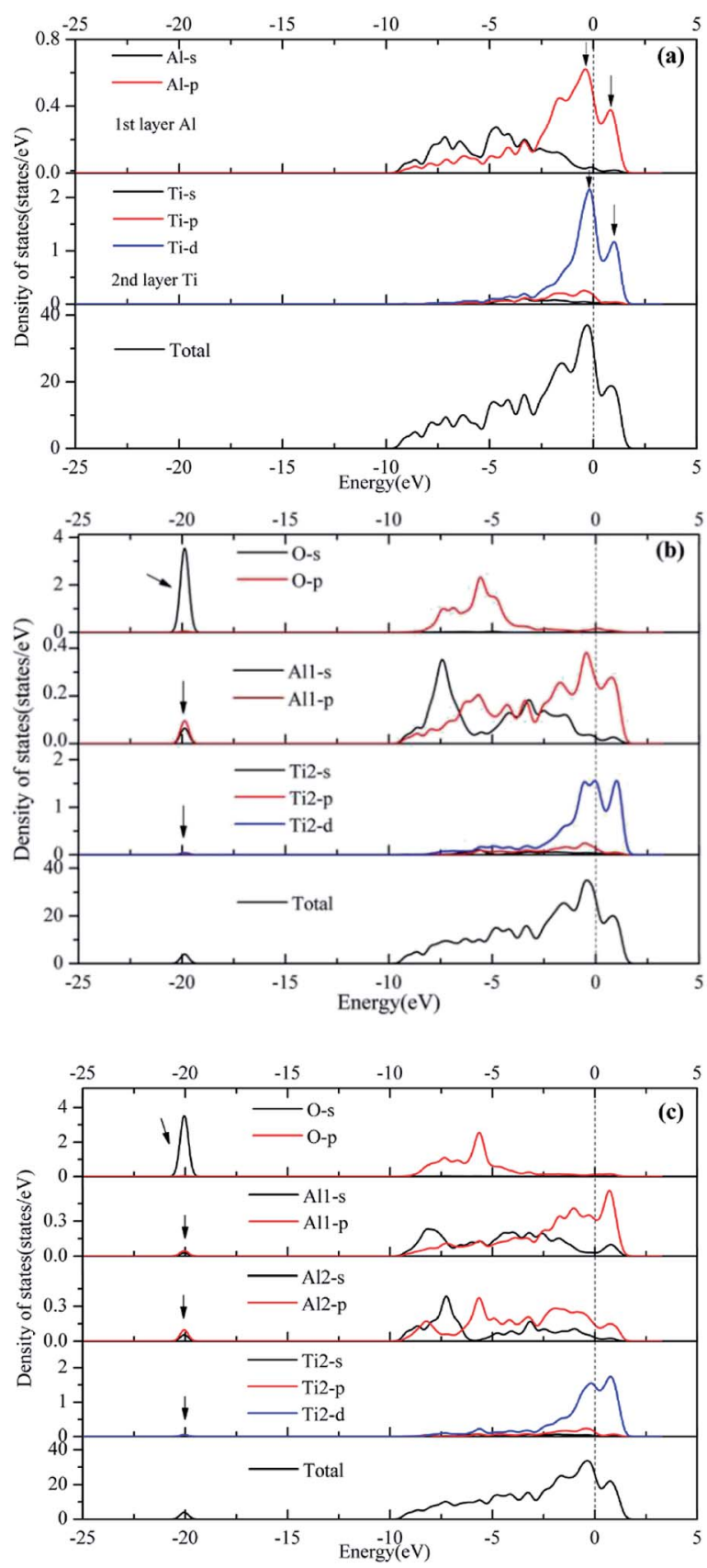

Fig. 7 Partial density of state (PDOS) and total density of state (TDOS) analyses of (a) free surface, (b) oxygen at the bridge1 site, (c) oxygen at the bridge 2 site. 


$$
\begin{gathered}
\mu_{\mathrm{Al}_{3} \mathrm{Ti}}^{\text {bulk }}=3 \mu_{\mathrm{Al}}^{\text {bulk }}+\mu_{\mathrm{Ti}}^{\text {bulk }}+\Delta H \\
\mu_{\mathrm{Al} 3 \mathrm{Ti}}^{\text {bulk }}=\mu_{\mathrm{Ti}}^{\text {slab }}+3 \mu_{\mathrm{Al}}^{\text {slab }}
\end{gathered}
$$

where $\mu_{\mathrm{Al}}^{\mathrm{bu}}$ and $\mu_{\mathrm{Ti}}^{\text {bulk }}$ are the single atomic energy of bulk $\mathrm{Al}$ and bulk Ti, respectively; $\Delta H$ is the formation enthalpy of $\mathrm{Al}_{3} \mathrm{Ti}$; and $\mu_{\mathrm{Al}_{3} \mathrm{Ti}}^{\text {bulk }}$ is the total energy of a unit cell. According to eqn (4) and (5),

$$
\mu_{\mathrm{Ti}}^{\text {bulk }}-\mu_{\mathrm{Ti}}^{\text {slab }}+\Delta H=3\left(\mu_{\mathrm{Al}}^{\text {slab }}-\mu_{\mathrm{Al}}^{\text {bulk }}\right)
$$

In view of the negative value of the formation enthalpy of bulk $\mathrm{TiAl}_{3}$ (the calculated value in this work was $-1.59 \mathrm{eV}$ per unit cell), the range of $\mathrm{Al}$ chemical potential $\left(\Delta \mu_{\mathrm{Al}}\right)$ was:

$$
\frac{1}{3} \Delta H<\Delta \mu_{\mathrm{Al}}=\mu_{\mathrm{Al}}^{\text {slab }}-\mu_{\mathrm{Al}}^{\text {bulk }}<0
$$

The surface energies of the low-index surfaces were calculated on the basis of the above formulas. As shown in Fig. 5, the surface energies of (100) and (111) do not depend on the chemical potential of $\mathrm{Al}$ due to their stoichiometric surfaces. However, the surface energies of the nonstoichiometric surfaces such as TiAl-terminated surfaces increased with the chemical potential of $\mathrm{Al}$, but the surface energies of the Al-terminated surfaces inversely decreased. The stability under Al-rich conditions was in the order of: (110)-Al > (001)-Al > (111) > (100) > (110)-AlTi > (001)-AlTi; under Al deficient conditions, the stability decreased in the order of: (110)-Al > (111) > (001)-Al > (001)-AlTi > (110)-AlTi. In all, the (110)-Al surface was stable under a wide range of $\mathrm{Al}$ chemical potentials.

\subsection{O adsorption on the (110)-Al surface}

According to the above calculations, the (110)-Al surface of $\mathrm{Al}_{3} \mathrm{Ti}$ was the most stable; thus, the behavior of oxygen atoms adsorbed on the surface were investigated to further reveal the oxygenation process. The calculated adsorption energies of oxygen at different sites on the (110)-Al surface are listed in Table 2. The adsorption site had a strong effect on the adsorption energy. The negative adsorption energies were indicative of a spontaneous adsorptions process. Moreover, the $E_{\text {ads }}$ of the $\mathrm{O}$ atoms at bridge sites were larger than those at Ti-hollow, Alhollow and Al-top sites, suggesting that $\mathrm{O}$ atoms preferentially adsorbed at the bridge positions. According to the comparison of adsorption energies, it could be concluded that the adsorption of $\mathrm{O}$ on the bridge 1 sites was more stable than on the bridge 2 sites. The initial distances between the $\mathrm{O}$ atoms and the nearest neighboring metal atom were about 3.5 $\AA$. After relaxation, the lengths of the $\mathrm{O}-\mathrm{Al} 1$ bond for the bridge 1 and bridge2 sites were $1.808 \AA$ and $2.218 \AA$ (Fig. 6a and b), respectively, which corresponds to the $\mathrm{O}-\mathrm{M}$ bond lengths in metal oxides. Therefore, the adsorption of oxygen might result in the formation of the corresponding oxides. In addition, when oxygen atom was adsorbed on bridge 2 position, the bonding strength of O-Al2 (1.861 $\AA$ ) was stronger than that of O-Al1 (2.218 $\AA$ ) (Fig. 6b), which indicated that the $\mathrm{O}$ atoms preferentially moved to the interstitial site.

Orbital hybridization and bonding characteristics were further analyzed according to the total and partial densities of states without and with $\mathrm{O}$ adsorption on the bridge sites (Fig. 7). For the free (110)-Al surface (Fig. 7a), two significant peaks that formed in the vicinity of Fermi energy led to strong metallic bonding. Moreover, the surface TDOS was mainly contributed from the interactions between Al-p and Ti-d orbitals. When an $\mathrm{O}$ atom was adsorbed on the bridge1 site (Fig. 7b), the peak height of the DOS of both the $\mathrm{Al}$ and $\mathrm{Ti}$ atoms decreased compared with those in the free surface sites, which suggested that the partial charges of the $\mathrm{Al}$ and $\mathrm{Ti}$ atoms were transferred to the $\mathrm{O}$ atom in the formation of strong covalent bonds. Meanwhile, clear hybridizations between $\mathrm{Al}$-sp and Ti-d orbitals occurred in the range of -10 to $2.5 \mathrm{eV}$. Additionally, weak interactions could also be observed between $\mathrm{O}-\mathrm{s}, \mathrm{Al}-\mathrm{s}, \mathrm{Al}-\mathrm{p}$ and Ti-d orbitals around $-20 \mathrm{eV}$ due to emergence of several new peaks for $\mathrm{O}, \mathrm{Al}$ and $\mathrm{Ti}$, and the region located around $-20 \mathrm{eV}$ was mainly dominated by O-s orbitals. Similar characteristics could also be found on the bridge2 site (Fig. 7c). The Mulliken charges and bond populations for $\mathrm{O}$ adsorption on the bridge 1 and bridge 2 sites are listed in Table 3. The Al1, $\mathrm{Al} 2$ and $\mathrm{Ti} 2$ in the two adsorption systems are defined in Fig. 6 . The charge transfers between the metal and $\mathrm{O}$ was the most obvious feature of the Mulliken charges in both the adsorption systems. The charge of the $\mathrm{Al} 2$ atom was larger than that of Ti2, which indicated that the $\mathrm{Al}$ atom exhibits greater electron loss than Ti. Furthermore, the bond population of $\mathrm{O}-\mathrm{Al} 2$ was larger than that of $\mathrm{O}-\mathrm{Ti} 2$, while

\begin{tabular}{|c|c|c|c|c|c|c|c|c|c|}
\hline $\begin{array}{l}\text { Adsorption } \\
\text { site }\end{array}$ & Atom & $\mathrm{S}$ & $\mathrm{p}$ & $\mathrm{d}$ & Total & Net $e$ & Bond type & Bond length & Population \\
\hline \multirow[t]{4}{*}{ bridge1 } & $\mathrm{O}$ & 1.88 & 5.03 & 0 & 6.91 & -0.91 & $\mathrm{O}-\mathrm{Al} 1$ & 1.808 & 0.41 \\
\hline & $\mathrm{Al} 1$ & 1.08 & 1.45 & 0 & 2.54 & 0.46 & $\mathrm{O}-\mathrm{Al} 2$ & 1.808 & 0.41 \\
\hline & $\mathrm{Al} 2$ & 1.08 & 1.45 & 0 & 2.54 & 0.46 & $\mathrm{O}-\mathrm{Ti} 2$ & 2.047 & 0.30 \\
\hline & $\mathrm{Ti} 2$ & 2.30 & 6.55 & 2.80 & 11.64 & 0.36 & & & \\
\hline \multirow[t]{4}{*}{ bridge2 } & $\mathrm{O}$ & 1.88 & 4.96 & 0 & 6.84 & -0.84 & $\mathrm{O}-\mathrm{Al} 1$ & 2.218 & 0.16 \\
\hline & Al1 & 1.25 & 1.53 & 0 & 2.87 & 0.22 & $\mathrm{O}-\mathrm{Al} 2$ & 1.861 & 0.34 \\
\hline & $\mathrm{Al} 2$ & 1.01 & 1.66 & 0 & 2.67 & 0.33 & O-Ti2 & 1.973 & 0.32 \\
\hline & $\mathrm{Ti} 2$ & 2.30 & 3.55 & 2.83 & 11.68 & 0.32 & & & \\
\hline
\end{tabular}
the bond length of $\mathrm{O}-\mathrm{Al} 2$ was shorter than that of $\mathrm{O}-\mathrm{Ti2}$. This indicates that the $\mathrm{O}$ atom preferentially bonds with an $\mathrm{Al}$ atom

Table 3 Mulliken charges, bond lengths $(\AA \AA)$ and populations of the bridge1 and bridge 2 adsorption systems 
rather than a Ti atom. Meanwhile, the available experimental data for the high-temperature oxidation of the $\mathrm{Al}_{3} \mathrm{Ti}$ alloy in an oxygenated atmosphere ${ }^{\mathbf{4 0 , 4 1}}$ has shown the formation of an outer protective oxide layer that almost completely consists of $\alpha$ $\mathrm{Al}_{2} \mathrm{O}_{3}$; this layer led to a suppressed oxygen diffusion, which significantly reduced the oxidation rate of the alloy. The theoretical and experimental results agreed with each other.

\section{Conclusions}

In summary, the structural, electronic and surface properties of the $\mathrm{Al}_{3} \mathrm{Ti}$ intermetallic alloy were investigated by the DFT method. The calculated bulk properties were in good agreement with the available experimental results. According to the density of states and surface energies, a nonstoichiometric (110) surface with Al termination was found to be the most stable surface. Strong hybridizations between O-p, Al-p and Ti-d orbitals contributed to the adsorption behavior of oxygen on the (110)-Al surface. The $\mathrm{O}$ atoms showed a preference for adsorption at the bridge 1 site based on the lowest adsorption energy. Density of state analysis revealed that the interaction between the $\mathrm{O}-2 \mathrm{p}$ and $\mathrm{Al}-2 \mathrm{p}$ orbitals is relatively strong, which promotes the formation of oxides like $\mathrm{Al}_{2} \mathrm{O}_{3}$ instead of pure protective alumina and negatively influences the oxidation resistance of $\mathrm{Al}_{3} \mathrm{Ti}$ intermetallic alloy.

\section{Conflicts of interest}

There are no conflicts to declare.

\section{Acknowledgements}

The research was financially supported by the National Natural Science Foundation of China (21865012 and 51874151), Jiangxi Natural Science Foundation of China (20181BAB216015 and 20181BAB203008) and Jiangxi province "5511" technology innovation platform plan project (20171BCD41002). This work was carried out in National Supercomputing Center in Shenzhen.

\section{Notes and references}

1 V. V. Ilyasov, K. D. Pham, G. E. Yalovega, I. V. Ershov, A. V. Ilyasov and C. V. Nguyen, Surf. Sci., 2016, 649, 20-26.

2 F. Wang, D. Eskin, J. Mi, T. Connolley, J. Lindsay and M. Mounib, Acta Mater., 2016, 116, 354-363.

3 Z. Lu, N. Wei, P. Li, C. Guo and F. Jiang, Mater. Des., 2016, 110, 466-474.

4 Z. Lu, F. Jiang, Y. Chang, Z. Niu, Z. Wang and C. Guo, Mater. Sci. Eng., A, 2018, 721, 274-285.

5 Z. Lu, N. Wei, P. Li, C. Guo and F. Jiang, Mater. Des., 2016, 110, 466-474.

6 R. Gupta and B. S. S. Daniel, Mater. Sci. Eng., A, 2018, 733, 257-266.

7 J. Y. Park, I. H. Kim, H. G. Kim, Y. I. Jung, D. J. Park, J. H. Park and Y. H. Koo, J. Nucl. Mater., 2015, 467, 607-611.
8 V. Maurice, G. Despert, S. Zanna, P. Josso, M. P. Bacos and P. Marcus, Acta Mater., 2007, 55, 3315-3325.

9 M. Schmitz-Niederau and M. Schutze, Oxid. Met., 1999, 52, 225-240.

10 S. Becker, A. Rahmel, M. Schorr and M. Schütze, Oxid. Met., 1992, 38, 425-464.

11 S. Chen, W. Zhang, Y. Zhang, G. Hu, T. Li, J. Shen and L. Zhou, Scr. Metall. Mater., 1992, 27, 455-460.

12 L. J. Parfitt, J. L. Smialek, J. P. Nic and D. E. Mikkola, Scr. Metall. Mater., 1991, 25, 727-731.

13 D. B. Lee, S. H. Kim, K. Niinobe, C. W. Yang and M. Nakamura, Mater. Sci. Eng., A, 2000, 290, 1-5.

14 J.-G. Kim, Y.-J. Choi, D.-B. Lee and M. Nakamura, Scr. Mater., 2000, 43, 579-584.

15 M. V. Karpets, Y. V. Milman, O. M. Barabash, N. P. Korzhova, O. N. Senkov, D. B. Miracle, T. N. Legkaya and I. V. Voskoboynik, Intermetallics, 2003, 11, 241-249.

16 N. Yamaguchi, T. Kakeyama, T. Yoshioka and O. Ohashi, Mater. Trans., 2002, 43, 3211-3216.

17 S. E. Kulkova, A. V. Bakulin, Q. M. Hu and R. Yang, Comput. Mater. Sci., 2015, 97, 55-63.

18 Y. Song, J. H. Dai and R. Yang, Surf. Sci., 2012, 606, 852-857. 19 H. Men, Mater. Res. Express, 2016, 3, 096501-096506.

20 S. Y. Liu, S. Liu, D. Li, T. M. Drwenski, W. Xue, H. Dang and S. Wang, Phys. Chem. Chem. Phys., 2012, 14, 11160-11166.

21 L. J. Wei, J. X. Guo, X. H. Dai, L. Guan, Y. L. Wang and B. T. Liu, Surf. Interface Anal., 2016, 48, 1337-1340.

22 B. Wang, J. Dai, X. Wu, Y. Song and R. Yang, Intermetallics, 2015, 60, 58-65.

23 S.-Y. Liu, J.-X. Shang, F.-H. Wang and Y. Zhang, Phys. Rev. B, 2009, 79, 075419.

24 S. E. Kulkova, A. V. Bakulin, Q. M. Hu and R. Yang, Comput. Mater. Sci., 2015, 97, 55-63.

25 S. J. Clark, M. D. Segall, C. J. Pickard, P. J. Hasnip, M. I. Probert, K. Refson and M. C. Payne, Z. Kristallogr. Cryst. Mater., 2005, 220, 567-570.

26 M. D. Segall, J. D. L. Philip, M. J. Probert, C. J. Pickard, P. J. Hasnip, S. J. Clark and M. C. Payne, J. Phys.: Condens. Matter, 2002, 14, 2717.

27 D. Vanderbilt, Phys. Rev. B: Condens. Matter Mater. Phys., 1990, 41, 7892-7895.

28 J. A. White and D. M. Bird, Phys. Rev. B: Condens. Matter Mater. Phys., 1994, 50, 4954-4957.

29 Q. Wu, S. Li, Y. Ma and S. Gong, Phys. B, 2012, 407, 23212328.

30 S. Saha, T. Z. Todorova and J. W. Zwanziger, Acta Mater., 2015, 89, 109-115.

31 G. Zhu, Y. Dai, D. Shu, Y. Xiao, Y. Yang, J. Wang, B. Sun and R. Boom, Intermetallics, 2011, 19, 1036-1040.

32 K. S. Kumar, Powder Diffr., 1990, 5, 165-166.

33 S. V. Meschel and O. J. Kleppa, Metallic Alloys: Experimental and Theoretical Perspectives, Springer Netherlands, Dordrecht, 1994, pp. 103-112.

34 J. H. Maas, G. F. Bastin, L. V. Fjj and R. Metselaar, Z. Metallkd., 1983, 74, 294-299.

35 P. Vajeeston, P. Ravindran, C. Ravi and R. Asokamani, Phys. Rev. B: Condens. Matter Mater. Phys., 2001, 63, 045115. 
36 C. D. Gelatt, A. R. Williams and V. L. Moruzzi, Phys. Rev. B: Condens. Matter Mater. Phys., 1983, 27, 2005-2013.

37 S. P. Sun, X. P. Li, H. J. Wang, H. F. Jiang, W. N. Lei, Y. Jiang and D. Q. Yi, Appl. Surf. Sci., 2014, 288, 609-618.

38 G. H. Chen, Z. F. Hou and X. G. Gong, Comput. Mater. Sci., 2008, 44, 46-52.
39 H. H. Xiong, H. N. Zhang and J. H. Dong, Comput. Mater. Sci., 2017, 127, 244-250.

40 Y. Umakoshi, M. Yamaguchi, T. Sakagami and T. Yamane, J. Mater. Sci., 1989, 24, 1599-1603.

41 J. L. Smialek and D. L. Humphrey, Scr. Metall. Mater., 1992, 26, 1763-1768. 